\title{
Human dermatophytosis acquired from pets: report of three cases
}

\section{Summary}

Dermatophytosis acquired from pets has been increasing. Dogs, cats and rodents are the more related animals with these superficial fungal infections. Microsporum canis and Trichophyton spp are the most common species involved in zoophilic dermatophytosis. We report three cases of dermatophytic infections acquired from infected pets and their etiological agents.

Keywords: dermatophytosis, pets, Microsporum canis, Trichophyton mentagrophytes, T erinaceii
Volume 2 Issue 4 - 2018

\author{
Patricia A Rodríguez,' Graciela Guzmán, ${ }^{2}$ \\ Paola García,' Daniel Asz-Sigall,' Roberto \\ Arenas' \\ 'Mycology Section, General Hospital, Mexico \\ ${ }^{2}$ Dermatologist from “Angeles Pedregal Hospital”, Mexico
}

Correspondence: Roberto Arenasa, General Manuel Gea González, Tlalpan 4800, Ciudad de México, CP I4080, México, Email rarenas98@hotmail.com

\section{Introduction}

Dermatophytosis also known as tineas are observed in domestic and wild animals; the more affected species are the small ones, like dogs and cats. They can affect any part of the hair covering, especially the head and face. ${ }^{1}$

According to environmental habitat, dermatophytes can be classified as:

i. Anthropophilic, whose natural habitat is the human being,

ii. Zoophilic, where natural habitat are animals and

iii. Geophilic that are found in the soil. Human infections are caused by close contact with infected animals. ${ }^{2}$

Cats and dogs are the most frequent animals involved with these fungi, mainly the genera Microsporum and Trichophyton. ${ }^{3}$ Dermatophytosis is one of the most frequent skin diseases in dermatologic attention in México. It can affect any sex, age, and any part of the body.

\section{Cases}

\section{First case}

On May 2017, a 7-year-old girl presented an erythematous, scaly and pruritic plaque on the right hand. Affecting palm and lateral parts of the fingers with pustules and vesicles. Also she had another plaque on the right thigh with a similar aspect with vesicular borders (Figure $1 \mathrm{~A} \& 1 \mathrm{~B})$. Her lesions had a 14-day history. The patient has a mouse and a recent adopted cat as pets. The $\mathrm{KOH}$ direct examination showed abundat hyphae. T. mentagrophytes was isolated and the specie was confirmed by PCR. The bacteriological culture was negative. The biopsy showed hyphae in the corneal layer and an inflammatory lymphocytic and eosinophilic infiltrate (Figure 2A \& 2B). The diagnose was inflammatory tinea manuum due to T. mentagrophytes and her treatment was with itraconazole $100 \mathrm{mg}$ every 48hours for a month with successful results. ${ }^{4}$

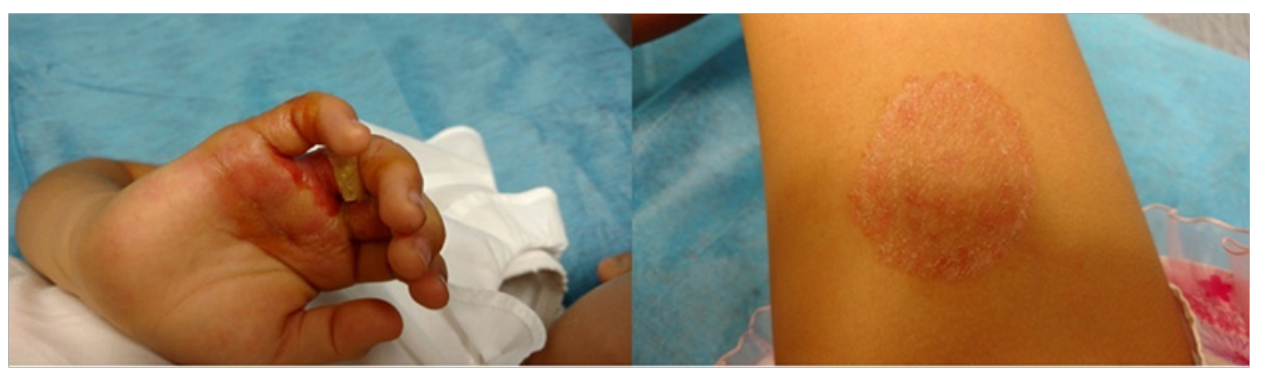

Figure I (A) Erythematous scaly plaque on the right hand and (B) the right thigh.

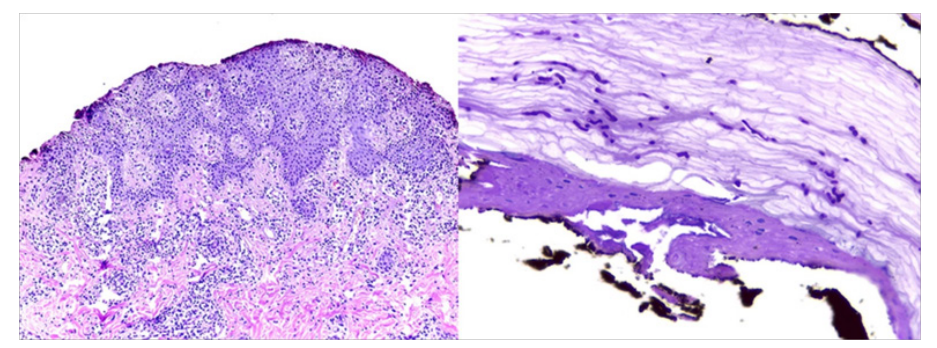

Figure 2 Biopsy shows hyphae within the stratum corneum and an inflammatory infiltrate. (A) PAS IOX, (B) 40X. 


\section{Second case}

A 10-year-old female patient presented erythematous scaly anular plaques with peripheral activity, pruritic; located on the neck, chest and nasogenian sulcus (Figure 3A \& 3B). She has an 8day history after buying a pet (chinchilla) (Figure 3A \& 3B). KOH direct examination with presence of hyphaes. By culture T.mentagrophytes was isolated. ${ }^{5}$
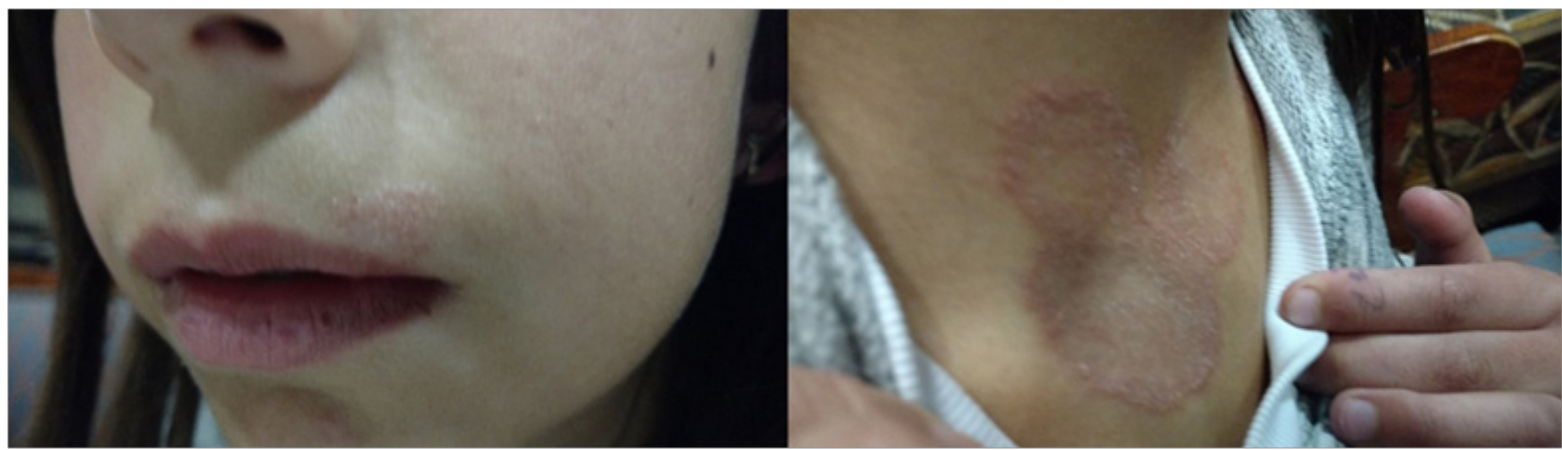

Figure 3(A) Nasogenian sulcus. (3B) Erythematous-scaly plaques with on the neck, front aspect of the chest.

\section{Third case}

OnDecember 2017, mother and her daughter came to dermatological consultation. They presented disseminated erythematous, scaly and pruritic plaques with active edges with a one month evolution (Figure 4A \& 4B). The 26-year-old mother presented several plaques in the maxillary region, and the 6-year-old daughter presented various lesions on the face predominantly on the forehead (Figure 4A \& 4B). They have a cat as pet. The $\mathrm{KOH}$ direct examination showed abundant hyphae (Figure 5). In Sabouraud dextrose agar Microsporum canis was isolated. Macroscopic examination of the culture is a white, fluffy and radiated strain. The microscopic examination shows macroconidia with thick walls and they have more than six septa (Figure 6A \& 6B). ${ }^{6}$

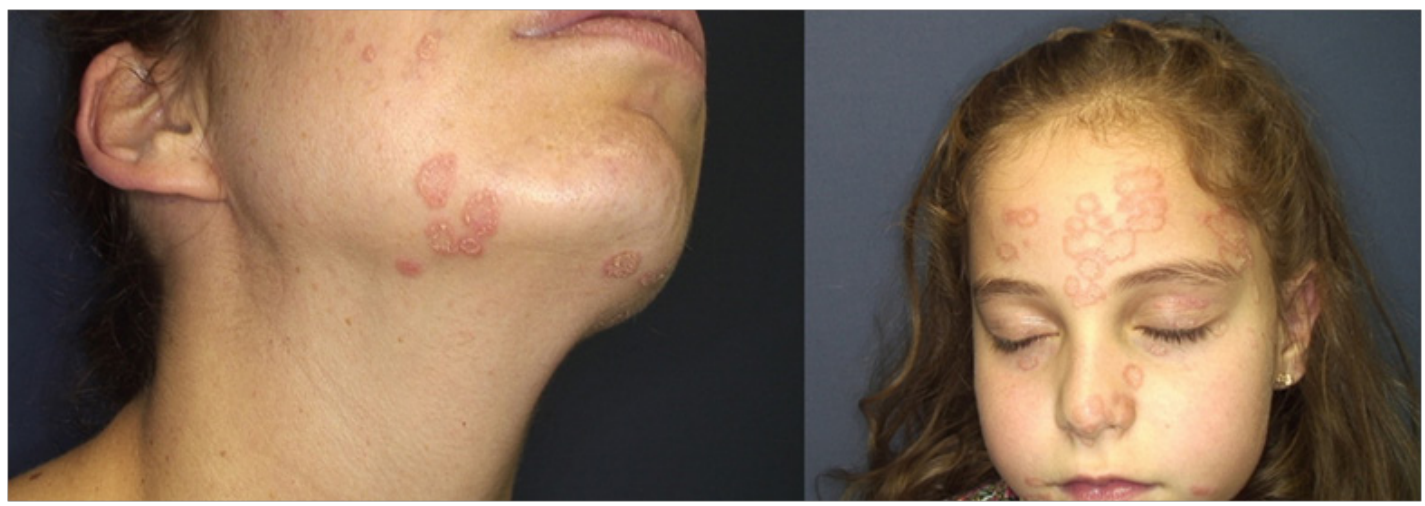

Figure 4 (A) Erythematous-scaly plaques on the neck and (B) on the face.

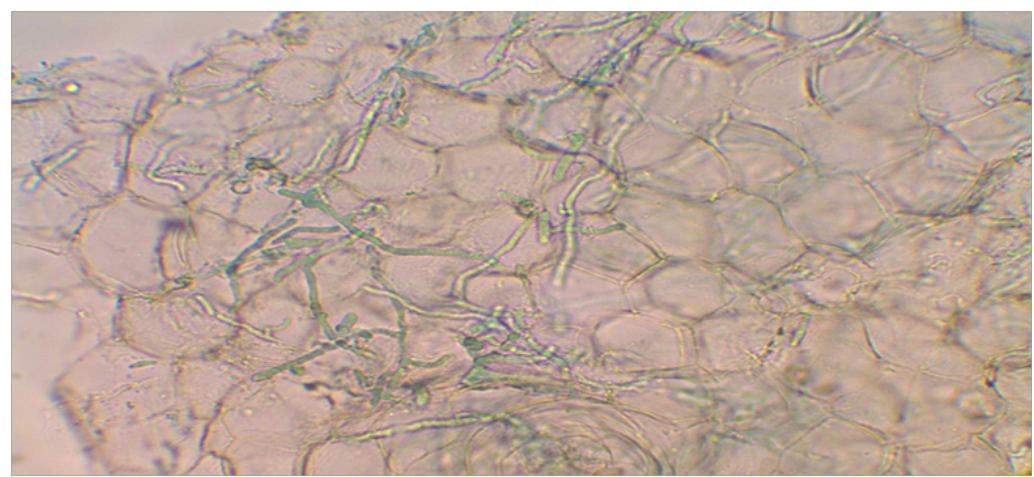

Figure 5 The $\mathrm{KOH}$ direct examination showed abundant hyphae. 


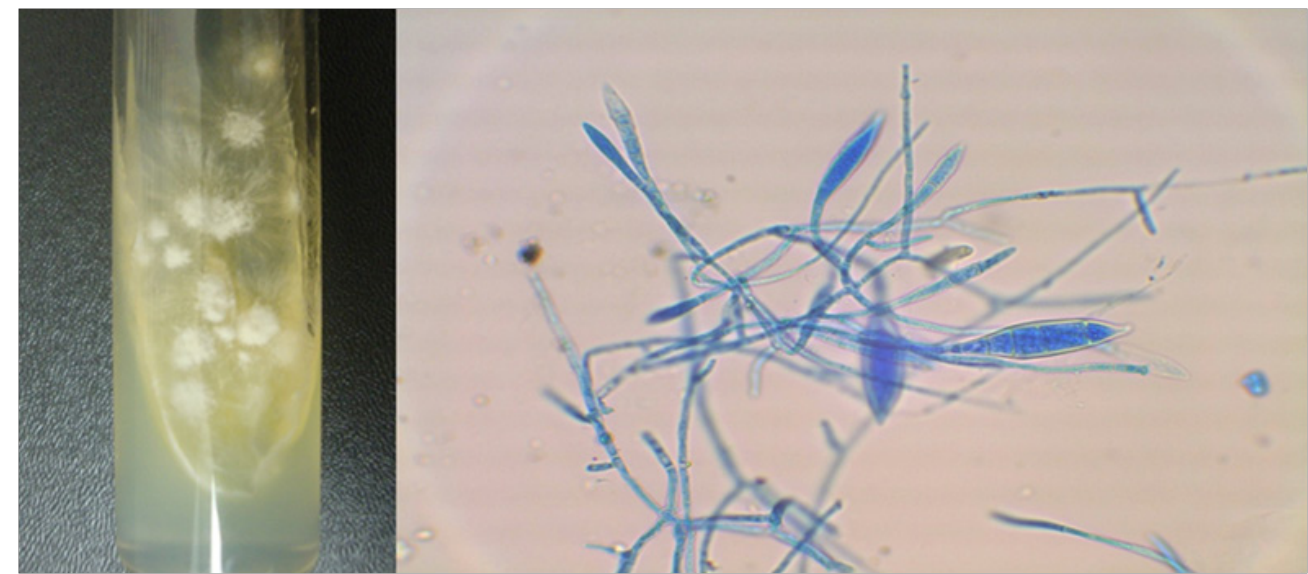

Figure 6 Macroscopic and microscopic aspect of the Microsporum canis.

\section{Discussion}

Dermatophytic infections are very common worldwide and the incidence increases every day because the increasing coexistence between humans and pets. Microsporum canis is the most frequent cause of infection in domestic animals with a high risk to infect the humans. ${ }^{7}$ Cats and dogs of long hair especially, can be carriers of M. canis. ${ }^{8}$ Rodents, rabbits and guinea pigs can be carriers of $T$. mentagrophytes. Clinical manifestations are alopecia and dry skin starting on the face and spreading along the back. ${ }^{8}$ Trichophyton mentagrophytes and Microsporum gypseum have been isolated from chinchillas. The skin and fur of these animals often harbors several superficial fungi. The infection of the skin in humans usually presents acute, inflammatory, tinea corporis or tinea capitis. ${ }^{9}$ Dermatophytes release proteolytic enzymes that induce inflammatory responses and result in typical clinical signs of erythema, pruritus, scaling and alopecia. Dermatophytic infections are common in pediatric and geriatric patients because of decreased host immunity. ${ }^{10}$ Diagnose is easy if doing a good clinic history, and mycological examination is gold standard because is quick and cheap.

\section{Direct examination}

Direct examination of dermatophytes with potassium hydroxide $(\mathrm{KOH})$ and chlorazol black allow us clearing specimens of keratin in order to visualize spores and hyphae. ${ }^{10}$

\section{Culture}

The cultures grow slowly and the fungal identification is performed ten to fifteen days later. Microscopic and macroscopic examination is important to get a precise result. ${ }^{2}$

\section{Other studies}

Examination the scalp with Woods's lamp may produce fluorescence in $30 \%$ to $80 \%$ of Microsporum canis infections. This lamp has an ultraviolet light through a cobalt or nickel filter. Hairs will fluoresce because of the tryptophan metabolites produced by the fungus. ${ }^{10} \mathrm{PCR}$ is useful when the mycological examination is not enough to identify the different species of dermatophytes. ${ }^{2}$ Treatments consist in oral or topical antifungal drugs or a combination of both, depending on the extension, severity, site of infection and causal agent. The main topical antifungal drugs include azoles and allylamine. A systemic treatment is recommended in infections that affect skin, annexes or very widespread lesions. ${ }^{2}$ Treatment duration varies from 4 to 6 weeks to get a total remission of the fungal infection.

\section{Conclusion}

Dermatophytic infections can affect anybody and one of the most important risks factors is the coexistence between humans and animals. The importance about dermatophytosis is to identify the causal agent in order to give a right treatment avoiding the development of tinea incognito when treated with corticosteroids.

\section{Acknowledgements}

None.

\section{Conflict of interest}

Author declares that there is no conflict of interest.

\section{References}

1. Roberto Arenas. Micología Médica Ilustrada. $5^{a}$ edition. México: McGraw-Hill;2014.

2. Monod M, Fratti M, Mignon B, et al. Dermatophytes transmis par les animaux domestiques. Med Suisse. 2014;10:749-753.

3. Noel F, Piérard-Franchimont C, Piérard GE, et al. Les champignons des villes et des champs, les animaux de compagnie et leurs propiétaires. Med Liège. 2011;66:11:589-595.

4. López-Cepeda L, Sánchez-Yarzagaray I. Tiña facial. A propósito de un caso con mecanismo de transmisión poco habitual. Rev Cent Dermatol Pascua. 2016;25(2):66-69.

5. Dabrowska I, Dworecka-Kaszak B, Billowska DA. The use of a one-step PCR method for the identification of Microsporum canis and Trichophyton mentagrophytes infection of pets. Acta ABP Biochimica Polonica. 2014;61(2):375-378.

6. Betancourt O, Salas V, Otarola A, et al. Microsporum canis en gatos dermatológicamente sanos en Temuco, Chile. Rev Iberoam Micol. 2009;26(3):206-210.

7. Fraile C, Zurutuza I, Valdivielso P. Dermatofitosis en animales de compañía: riesgo zoonótico. In: Canosa P, Minguell F. El niño y los animales de compañía. $3^{\mathrm{a}}$ Edition. España:Elsevier;2013.

8. Rosen T, Jablon J. Infectious threats from exotic pets: dermatological implications. Dermatol Clin. 2003;21(2):229-236. 
9. Marshall KL. Fungal disease in small mammals: therapeutic trends and zoonotic considerations. Vet Clin North Am Exot Anim Pract. $2003 ; 6(2): 415-427$
10. Sahni K, Singh S, Dogra S. Newer topical tratments in skin and nail dermatophyte infections. Indian Dermatol Online J. 2018;9(3):149-158. 